ORIGINAL ARTICLE

\title{
Mild head injury: observation or computed tomography? Economic aspects by literature review and decision analysis
}

\author{
J-L af Geijerstam, M Britton, L-Å Marké
}

Emerg Med J 2004;21:54-58

See end of article for authors' affiliations

.....................

Correspondence to: Jean-Luc of Geijerstam, Department of Medicine N4:01, Unit of Clinical Epidemiology, Karolinska Hospital, SE-171 76 Stockholm, Sweden; jean-luc.af.geijerstam@ medks.ki.se

Accepted for publication 3 January 2003

\begin{abstract}
Objectives: To compare the costs of two strategies for acute management of mild head injury: inhospital observation compared with acute computed tomography (CT) and home care.

Methods: Studies comparing costs for the two strategies that seem to have similar outcomes for patients were systematically reviewed. A decision tree analysis to compare the costs was also constructed, based on Swedish national costs and the risks found in a recent review on mild head injury complications.

Results: No studies were found that directly measured and compared risks, benefits, and costs of the two strategies. In the four studies retrieved, involving 4126 patients, the costs for hospital observation were factual, but a model was used to evaluate costs for the CT strategy. On average, costs were one third lower with CT. Also, the decision tree analysis demonstrated that the CT strategy was one third less expensive than inhospital observation. A sensitivity analysis showed this to be valid for nearly all cases. If these calculations hold true, a change of strategy could result in annual savings of $£ 280 \mathrm{000} / \mathrm{million}$ inhabitants.

Conclusion: The $\mathrm{CT}$ strategy seems to cost one third less than hospital observation.
\end{abstract}

M ild head injury is one of the most common reasons for hospital admission after trauma. Annually, 17000 patients (190/100 000 inhabitants) are admitted with mild head injuries in Sweden. ${ }^{1}$ Direct costs for the acute management of mild head injury in Sweden are estimated to be $£ 7.6$ million annually, £84 000/100 000 inhabitants. ${ }^{2}$ The indirect costs could not be reliably estimated, but seem to be considerably higher than the direct costs.

No uniform guidelines for the care of mild head injury are broadly accepted. Sweden and many other European countries have a longstanding tradition of managing mild head injury with inhospital observation..$^{3-7}$ Some of the admitted patients receive a computed tomography (CT) scan in addition to inhospital care, around $20 \%$ in Sweden. ${ }^{4}$ The question has been raised concerning whether all patients with mild head injury instead can be triaged for admission with an early CT scan. ${ }^{8}$ Unnecessary admissions of patients with normal CT findings might thereby be avoided, and better care provided for patients with abnormal CT findings and at higher risk for deterioration with need for surgery or more intensive care. In our recent review of complications from mild head injury we estimated that even with the CT strategy at least $8 \%$ of the patients will require inhospital care because of abnormal CT findings or complications. ${ }^{9}$ It is also possible that an additional $10 \%$ might require admission because of organisational, medical, or social reasons despite normal CT findings.

The use of skull radiography to triage patients with mild head injury for admission or for CT has been discussed. ${ }^{10}{ }^{11}$ In Sweden, this method is not used routinely. ${ }^{4}$ Most evidence shows that skull radiography is less informative than CT and of limited value for the management of head injuries of a milder degree. ${ }^{12}{ }^{13}$ Furthermore, skull radiography carries a cost similar to CT, which even further lessens its value in a clinical setting where CT is available. ${ }^{14}$ For these reasons, CT seems to be the method of choice for admission triage in mild head injury and therefore the focus of this review.

Because of the high volume of patients with mild head injury, their management consumes considerable economic resources. Different management strategies for these patients have both medical and economic implications. The overall question is: Would a CT based strategy for patients with mild head injury be more effective or less costly than one based on inhospital observation? In general, there are few well designed studies of these patients. ${ }^{13}$ In fact, there is not a single randomised trial of strategies for their acute management. In a previous systematic review we found that no studies at all directly compared the medical risks and benefits of inhospital observation with those of CT and discharge. ${ }^{2}$ Both strategies appeared to be safe, with few reported severe complications and deaths. Other reviews have also pointed out the lack of properly designed, comparative trials and an absence of consistent definitions and measures of outcomes in head injury research. ${ }^{11}{ }^{13} 15$ This review considers the health economics of the two strategies. As there is presently not sufficient evidence to assign superiority in medical outcome to either one of the two strategies, the following analysis is performed as a cost minimisation study.

A search of the literature for cost comparisons regarding the two strategies was one way to find which was the least expensive, another was a decision tree analysis based on Swedish national costs and the probabilities found in our recent review. ${ }^{9}$

\section{METHODS \\ Definitions}

Mild head injury

The definition of mild head injury used in this report is short term loss of consciousness or amnesia, or both, as a result of skull trauma. Upon presenting in the emergency department, the patient should have regained a normal level of consciousness as measured by the Glasgow coma scale $(\text { GCS })^{16}$ and have normal neurological findings. Some definitions of mild head injury include GCS $13-15 .{ }^{17}$ The evidence shows that patients with GCS 13-14 have a significantly greater overall risk compared to patients with GCS $15 .{ }^{18}$ As the situation for patients with GCS 13-14 is more serious, the best group in which to initially try the home care strategy would be GCS 15. They also constitute the vast 
majority of patients with mild head injury. ${ }^{10}$ For these reasons, only GCS 15 was included in our analysis.

\section{Abnormal CT}

The frequency of abnormal findings from CT varies among studies depending on the definition used. Our review covers all abnormal CT findings that could be attributed to the head trauma. This includes intracranial bleeding (which dominates), skull fractures, and oedema.

\section{Complication}

Complication is defined broadly to include neurosurgical operation (which dominates), medical treatment of brain oedema, intracranial pressure monitoring and transfer to more intensive care.

\section{The review process}

Medline was searched from 1966 to May 2002. There are no generally accepted definitions for mild head injury, and indexing in the databases has changed over time. Hence, we conducted a broad search using multiple keywords in different combinations (see appendix for a full list of search terms). The Cochrane Library and OHE-HEED (a database of health economic studies) were also screened, as were reference lists of key studies and review articles. Studies in any language were accepted.

\section{Costs according to literature}

Relevant studies containing economic aspects were reviewed according to the principles proposed by Drummond et al. ${ }^{19}$ In our evaluation a study could at best fulfil all of Drummond's 10 criteria, which are grouped under three headings: study design, data collection and analysis, and interpretation of results. As discounting does not fully apply to patients with short term outcomes, a maximum number of seven criteria are evaluated in this case.

\section{Decision tree analysis}

Decision tree analysis was used to compare the two strategies (Data 3.5 for healthcare, Treeage software, 1999).

The point at which a decision is made-that is, CT or inhospital observation-is marked with a box in figure 1 . The two strategies end with circles, called "chance nodes". Triangles are placed at the end of each outcome. Costs were calculated for all branches and totalled for each of the two strategies.

To estimate the costs in the decision tree analysis, we used Swedish national data on inhospital care for all patients with mild head injury (table 1). ${ }^{12491420}$ Average costs were used as the care of the great majority of patients admitted to the ward follow an uncomplicated course. Only direct costs in the acute phase were included in the analysis. All costs are presented in sterling $(£)$ ( $£ 1$ in $1998=13.17$ SEK/1.66 US\$). Rare events that did not affect the calculations were excluded in the figure to give a better overview (for example, readmission after normal $\mathrm{CT}$ with $\mathrm{CT}$ strategy and readmission after observation with observation strategy). The time span of the decision analysis is two days as the mean number of inpatient days in Sweden is 1.4 for patients with mild head injury. ${ }^{2}$ Furthermore, the lack of data on differences in medical outcome in the acute phase as well as long term, renders further comparison of the two strategies impossible.

The nature of clinical practice requires a mix of strategies. Therefore, the most probable scenario presupposes that $10 \%$ of patients would be admitted under the CT strategy despite normal CT findings (in addition to the $8 \%$ with abnormal CT findings). With the observation strategy $20 \%$ of patients would receive a CT scan despite being admitted, which was the mean in Sweden in 1998.

To test the robustness of the conclusions, probabilities, and costs were changed in a sensitivity analysis. Details concerning this analysis are found in figure 2 .

\section{RESULTS}

\section{Costs according to literature}

Our literature search did not yield any economic studies of mild head injury where actual costs were measured and compared in patients managed under the two strategies. We found 12 studies containing economic aspects on these patients. Eight of the studies were excluded because they only discussed costs and did not report any findings, ${ }^{321}{ }^{22}$ or dealt only with the use of plain skull radiography..$^{23-27}$

The four remaining studies used a model to estimate the costs of a CT strategy and compared them with real costs for patients admitted for inhospital observation (table 2). ${ }^{28-31}$ All studies were cost minimisation analyses based on data from 1985 to 1994. One was from Norway and three were from the United States.

All four studies fulfilled four of seven possible criteria for economic evaluations according to Drummond. In this regard, all had the same shortcomings: they used a model to estimate the cost of a CT strategy and no allowance for uncertainty was given (statistical significance, sensitivity analysis).

Included patients did not adhere strictly to the present definition of mild head injury as GCS 13-15 and 14-15 were accepted. In all four studies, a large majority of the patients had GCS 15, and they were therefore used. The inclusion of a few patients with GCS 13-14 most probably disfavours the CT

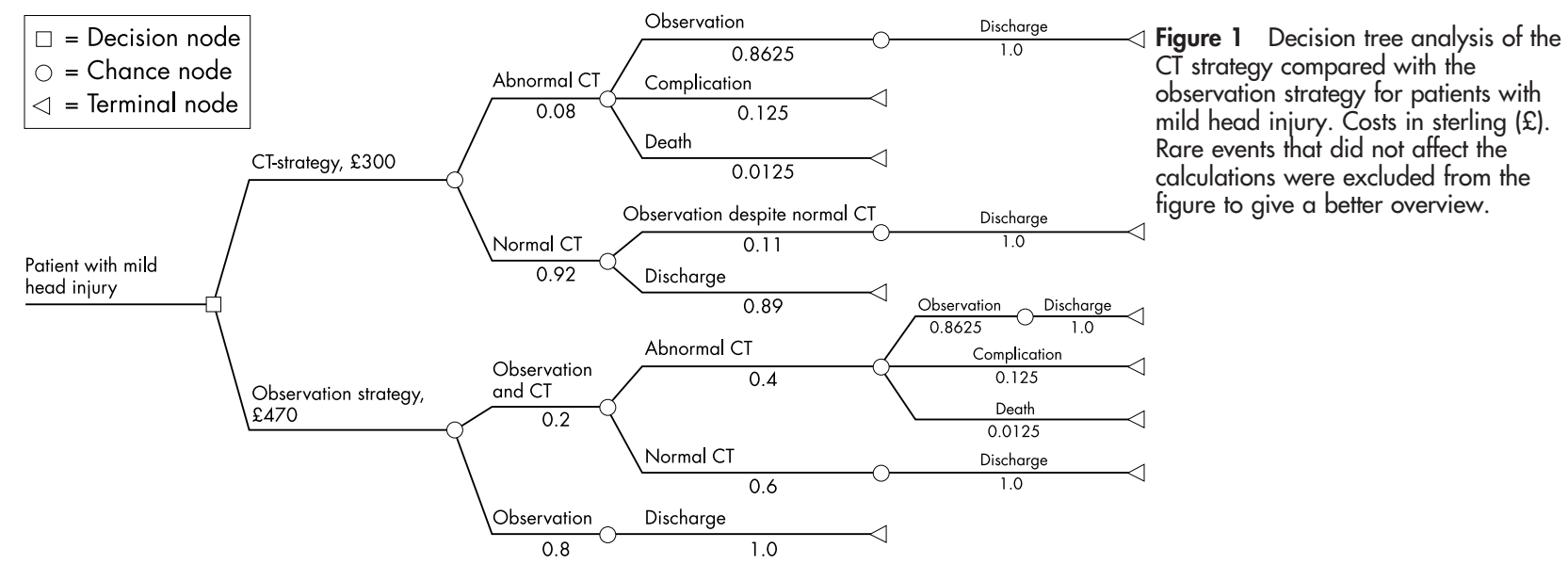


Table 1 Items used to calculate the direct costs for the acute management of mild head injury in Sweden where the current strategy is based on inhospital observation. Costs in sterling (£), 1998

\begin{tabular}{lll}
\hline & & Reference \\
\hline Number of cases (inhospital stay $\leqslant 3$ days) & 15917 & 1 \\
Patient days (inhospital stay $\leqslant 3$ days) & 22284 & 1 \\
Use of CT in admitted patients & $20 \%$ & 4 \\
Mortality & $0.1 \%$ & 9 \\
Need for intervention & $1 \%$ & 9 \\
Abnormal findings of acute CT & $8 \%$ & 2 \\
Cost of CT scan, mean & 135 & 20 \\
Cost of observation (1.4 patient days), mean & 335 & 14 \\
Cost of emergency department visit, mean & 75 & 14 \\
Cost of neurosurgery & 3800 & \\
\hline
\end{tabular}

strategy slightly in regards to costs. The frequency of abnormal findings on CT is higher in this group as compared with GCS 15, and more patients will subsequently require admission. Therefore, an economic advantage with CT and home care will be underestimated.

All four studies concluded that a CT based strategy for mild head injury would be less costly than one based on inhospital observation, and would decrease costs between $8 \%$ and $54 \%$ (table 2). On average, the costs would be one third lower. The absolute costs differ among the studies because of differences in what the calculations included. In the study reporting the least difference in costs between the two strategies, only $8 \%$, the cost per bed day and the cost of a CT scan were about equal. In the three other studies the cost of a CT scan was considerably lower than a hospital bed day.

\section{Decisions tree analysis}

The decision analysis is presented in figure 1. The tree illustrates the probabilities for patients managed by the CT strategy compared with the observation strategy. Then, costs belonging to each outcome of all the branches are calculated and totalled for the two strategies. The cost of the CT strategy seems to be $36 \%$ lower than the cost for inhospital observation, or $£ 300$ compared with $£ 470$. This difference is explained mainly by the lower cost of a CT scan as compared with inhospital care.

To apply the results in different healthcare settings it is necessary to assess resource use separately from costs. The resource use of the two strategies (number of CT scans carried out and number of bed days consumed) is found in the data for the decision tree analysis. Application of local

\section{How to read the table:}

The sensitivity analysis varies the following factors:

- Cost of inhospital observation, £260-410

- Cost of CT scan, £60-215

- CT strategy: percentage of patients admitted despite normal CT findings, $10 \%$ to $30 \%$

- Observation strategy: percentage of patients given a CT scan despite observed in hospital, $10 \%$ to $30 \%$

This illustrated below with the most likely scenario (box in the middle of the table, 36 ).

- The cost of inhospital observation is $£ 335$, and the cost of CT scan is $£ 140$.

- In this case, the number of patients admitted despite normal CT findings was $10 \%$, and $20 \%$ of the patients observed received a CT scan. This means that the cost of the CT strategy would be $36 \%$ lower than that of inhospital observation (see box in table)

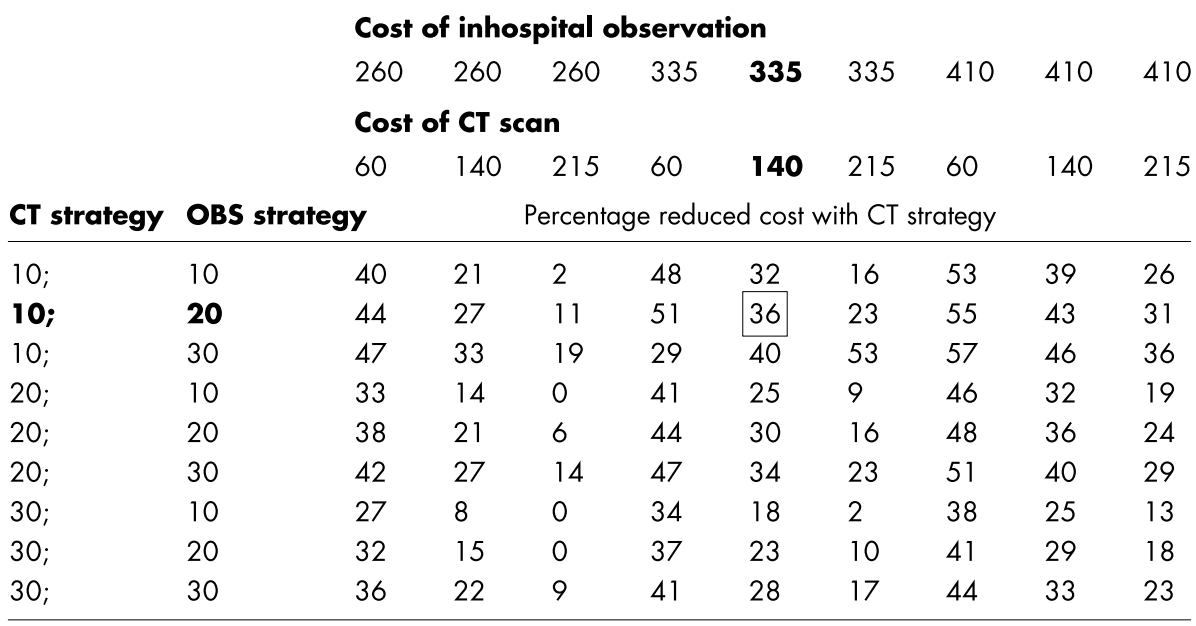

Figure 2 Sensitivity analysis of costs for a CT strategy compared with an observation strategy for mild head injury. 
Table 2 Economic studies of patients with mild head injury where costs of inhospital observation are compared with a CT based strategy. Costs in sterling (£), 1998.

\begin{tabular}{lcclll}
\hline $\begin{array}{l}\text { Author, year, } \\
\text { country, } \\
\text { reference }\end{array}$ & $\begin{array}{l}\text { Number of } \\
\text { patients }\end{array}$ & GCS & $\begin{array}{l}\text { In hospital } \\
\text { observation } \\
\text { (cost/patient) }\end{array}$ & $\begin{array}{l}\text { CT strategy } \\
\text { (cost/patient) }\end{array}$ & $\begin{array}{l}\text { Cost reduction with } \\
\text { CT strategy (\%) }\end{array}$ \\
\hline $\begin{array}{l}\text { Stein, 1991, } \\
\text { USA }^{28}\end{array}$ & 658 & $13-15$ & 725 & 665 & 8 \\
$\begin{array}{l}\text { Shackford, } \\
\begin{array}{l}\text { 1992, USA } \\
\text { Dacey, 1986, }\end{array}\end{array}$ & 2766 & $13-15$ & 1160 & 765 & 34 \\
$\begin{array}{l}\text { USA } \\
\text { Ingebrigtsen, } \\
\text { 1996, Norway }\end{array}$ & 611 & $13-15$ & 1460 & 675 & 54 \\
$\begin{array}{l}\text { Total number of } \\
\text { patients }\end{array}$ & 4126 & $14-15$ & 485 & 315 & 35 \\
\hline & & & & \\
GCS, Glasgow coma scale. & & & & \\
\hline
\end{tabular}

costs (cost of CT scan, cost of bed day) to these assumptions allows for a simple application of the findings in different settings.

The sensitivity analysis is presented in figure 2. It shows that the CT strategy yields lower costs in 78 of 81 possible situations when probabilities and costs are varied within reasonable limits. It also shows that in 27 cases the CT strategy would reduce costs more than the $36 \%$ presented in our main assumption. In three cases the costs are equal, and none show a higher cost associated with the CT strategy.

In this case, the number of patients admitted despite normal CT findings was $10 \%$, and $20 \%$ of the patients observed received a CT scan. This means that the cost of the CT strategy would be $36 \%$ lower than that of inhospital observation (see box in figure 2).

\section{DISCUSSION}

There are no economic studies of mild head injury where actual costs are measured and compared in patients managed under the two strategies-that is, inhospital observation compared with CT to triage for admission.

Based on model calculations in four studies from two countries it seems as if a CT based strategy would consume fewer resources. The ratio between the cost of a CT scan and the cost per day and length of inhospital observation is central for our cost analysis. Our cost of illness calculations in Sweden found the ratio to be around $0.4(=$ cost of CT scan compared with the cost of average 1.4 bed days). We believe that the ratio is roughly similar throughout many industrialised countries. Of course, the applicability of a CT strategy also depends on the national structure of acute care, especially the availability of CT scanners.

The sensitivity analysis shows that within a realistic span of variation the CT strategy would be less costly. In addition, current changes in clinical practice in Sweden indicate a move towards an increase in the use of CT despite admission. Such a trend favours a CT strategy even further in regard to costs.

Lower costs with a CT strategy presume adherence to the definition of mild head injury. If previously non-admitted patients are scanned the total cost could rise. Also, the lower total costs presume that many patients with a normal CT scan will be discharged. It could also be argued that earlier diagnosis may increase costs by increasing ICU stay or surgical intervention. However, the complete opposite is also fully conceivable. A prospective randomised trial with patient follow up will be the only way to get really reliable evidence regarding the risks, benefits and costs of different management strategies for mild head injury.
In conclusion, a substantial body of indirect evidence suggests that a CT strategy for the acute care of mild head injury is resource saving.

\section{ACKNOWLEDGEMENTS}

A systematic literature review was originally carried out for the Swedish Council on Technology Assessment in Health Care (SBU) and published in a Swedish governmental report in December 2000. The SBU Project Group on Mild Head Injury included Mona Britton (project chair) Jörgen Borg, Mia Colliander, Jean-Luc af Geijerstam (project coordinator), Kaj Ericson, Lars-Åke Marké, Johan Nathorst Westfelt, Sven Oredsson, and Elisabeth Ronne-Engström. This report has now been updated, shortened, and focused more on scientific aspects.

\section{Authors' affiliations}

J-L af Geijerstam, M Britton, L-Å Marké, The Swedish Council on Technology Assessment in Health Care (SBU)

$\mathrm{J}$-L af Geijerstam, M Britton, Department of Medicine, Unit of Clinical Epidemiology, Karolinska Hospital, Stockholm, Sweden

Funding: this study was supported by The Swedish Council on Technology Assessment in Health Care (SBU).

\section{APPENDIX}

\section{SEARCH TERMS}

Brain concussion; brain injuries; case reports; cerebral haemorrhage; closed head injuries; CT; diagnosis; diagnostic errors; emergency service, hospital; follow up studies; haematoma (epidural, subdural); head injuries; mild brain injury; mild head injury; minimal brain injury; minimal head injury; minor brain injury; minor head injury; monitoring, physiological; mortality; radiography; review, guidelines; risk assessment; risk factors; sensitivity, specificity; survival rate; tomography, $\mathrm{x}$-ray computed; triage.

\section{REFERENCES}

1 Centre for Epidemiology, National Board of Health and Welfare. In hospital care 1996. Patients, admissions and length of stay. Database. Stockholm: Centre for Epidemiology, National Board of Health and Welfare, 1998.

2 The Swedish Council on Technology Assessment in Health Care. Mild head injury-in-hospital observation or computed tomography? Report no153. [In Swedish, summary in English at http://www.sbu.se). Stockholm: SBU (The Swedish Council on Technology Assessment in Health Care), 2000.

3 Brell M, Ibanez J. [Minor head injury management in Spain: a multicenter national survey]. Neurocirugia (Astur) 2001;12:105-24.

4 af Geijerstam J-L, Britton M, Mebius C. Management of minor head injuries in emergency departments in Sweden. Time for a new strategy? Eur J Surg 2000;166:526-9.

5 Ingebrigtsen T, Romner B. Management of minor head injuries in hospitals in Norway. Acta Neurol Scand 1997;95:51-5.

6 von Wild K, Terwey S. Diagnostic confusion in mild traumatic brain injury (MTBI). Lessons from clinical practice and EFNS-inquiry. European Federation of Neurological Societies. Brain Inj 2001;15:273-7. 
7 Williams RJ, Hittinger R, Glazer G. Resource implications of head injuries on an acute surgical unit. J R Soc Med 1994;87:83-6.

8 Stein SC, Ross SE. The value of computed tomographic scans in patients with low-risk head injuries. Neurosurgery 1990;26:638-40.

9 af Geijerstam J-L, Britton M. Mild head injury-mortality and complication rate: meta-analysis of findings in a systematic literature review. Acta Neurochir (Wien) 2003;145:843-50.

10 Teasdale GM. Head injury. J Neurol Neurosurg Psychiatry 1995;58:526-39.

11 Servadei F, Teasdale G, Merry G. Defining acute mild head injury in adults: a proposal based on prognostic factors, diagnosis, and management. J Neurotrauma 2001; 18:657-64.

12 Masters SJ, McClean PM, Arcarese JS, et al. Skull x-ray examinations after head trauma. Recommendations by a multidisciplinary panel and validation study. N Engl J Med 1987;316:84-91.

13 Jagoda AS, Cantrill SV, Wears RL, et al. Clinical policy: neuroimaging and decisionmaking in adult mild traumatic brain injury in the acute setting. Ann Emerg Med 2002;40:231-49.

14 Southern health care district. Regional pricelist 1998. [In Swedish]. Lund: Southern health care district, co-operation committee, 1997.

15 Narayan RK, Michel ME, Ansell B, et al. Clinical trials in head injury. J Neurotrauma 2002; 19:503-57.

16 Teasdale G, Jennett B. Assessment of coma and impaired consciousness. A practical scale. Lancet 1974;ii:81-4.

17 Borczuk P. Mild head trauma. Emerg Med Clin North Am 1997;15:563-79.

18 Culotta VP, Sementilli ME, Gerold K, et al. Clinicopathological heterogeneity in the classification of mild head injury. Neurosurgery 1996;38:245-50.

19 Drummond $M$, Jefferson T. Guidelines for authors and peer reviewers of economic submissions to the BMJ. BMJ 1996;313:275-83.

20 Swedish Federation of County Councils. Cost per admitted patients 1996. [In Swedish]. Stockholm: Swedish Federation of County Councils, 1999.
21 Mitchell KA, Fallat ME, Raque GH, et al. Evaluation of minor head injury in children. J Pediatr Surg 1994;29:851-4.

22 Livingston DH, Loder PA, Koziol J, et al. The use of CT scanning to triage patients requiring admission following minimal head injury. J Trauma 1991;31:483-7, 487-9.

23 Baker SR, Gaylord GM, Lantos G, et al. Emergency skull radiography: the effect of restrictive criteria on skull radiography and CT use. Radiology 1985; 156:409-13.

24 Jones JJ, Jeffreys RV. Relative risk of alternative admission policies for patients with head injuries. Lancet 1981;ii:850-3.

25 Mendelow AD, Campbell DA, Jeffrey RR, et al. Admission after mild head injury: benefits and costs. BMJ Clin Res Ed 1982;285:1530-2.

26 Stalhammar D. Resources, distribution and management levels of head injury patients; place of CT-scanning. Acta Neurochirurg Suppl (Wien) 1986;36:63-6.

27 Vydareny KH, Harle TS, Potchen EJ. An algorithmic approach to the roentgenographic evaluation of head trauma: medical and financial implications. Invest Radiol 1983;18:390-5.

28 Stein SC, O'Malley KF, Ross SE. Is routine computed tomography scanning too expensive for mild head injury? Ann Emerg Med 1991;20:1286-9.

29 Shackford SR, Wald SL, Ross SE, et al. The clinical utility of computed tomographic scanning and neurologic examination in the management of patients with minor head injuries. J Trauma 1992;33:385-94.

30 Dacey RG Jr, Alves WM, Rimel RW, et al. Neurosurgical complications after apparently minor head injury. Assessment of risk in a series of 610 patients. J Neurosurg 1986;65:203-10.

31 Ingebrigtsen T, Romner B. Routine early CT-scan is cost saving after minor head injury. Acta Neurol Scand 1996;93:207-10. 